\title{
Modeling of hole geometrical features in laser drilling of AISI316L sheet
}

\author{
Satish Namdev*, Anand Pandey**, Arun Kumar Pandey*** and Rakesh Kumar**** \\ *Department of Mechanical Engineering, Government Polytechnic Adampur, Tarabganj, Gonda, Uttar Pradesh -271401, India. \\ **Department of Mechanical Engineering, Manipal University Jaipur, Jaipur-303007, India. \\ ***Department of Mechanical Engineering, Bundelkhand Institute of Engineering \& Technology, Jhansi-284128, India. \\ ****Department of Automobile Engineering, Manipal University Jaipur, Jaipur-303007, India. \\ *Corresponding Author: satishnamdev@gmail.com
}

$\begin{array}{ll}\text { Submitted } & : 18 / 05 / 2020 \\ \text { Revised } & : 24 / 03 / 2021 \\ \text { Accepted } & : 11 / 04 / 2021\end{array}$

\begin{abstract}
Micro-drilling of AISI316L is an extremely challenging task. Unconventional machining process may be used for such type of operation. Laser beam drilling is the best for micro-drilling. High thermal energy and convergingdiverging property of laser beam affect the quality of laser drilled holes. In the present work, Nd:YAG laser beam has been used, and we investigate the effects of laser input parameters on responses. To minimize the number of experiments, we get extreme information for experimental trials. Central composite rotatable design approach has been adopted. Analysis of variance is used to find reliable input parameters affecting responses. From this paper, it is found that current and gas pressure are significant for hole circularity at top. Current and pulse frequency are significant for bottom side circularity. Current and cutting speed are significant parameters for hole taper.
\end{abstract}

Keywords: LBD; ANOVA; RSM; AISI316L; Hole taper; Hole circularity.

\section{INTRODUCTION}

Micro-drilling is an extremely difficult task for modern materials. Stainless steel material AISI316L is one of them and has many applications in medical, automotive, aeronautics, and aerospace industries. Because AISI316L material has unique material properties like high thermal conductivity, high corrosion resistance, and high strength etc., AISI316L is a bio-compatible material. It is used as orthopedic material. It is also widely used for biomedical applications and bio-industries [E. Audouard et al., 2017 \& A. Bharatish et al., 2013].

Nowadays, laser drilling is used in medical industries, automobile sector, and many more industries. Its unique properties like no tool wear, no contact between tool and work piece, low wastage of materials, precise hole features, micro-machining make it more special than other conventional machining processes [A. Cekic et al., 2014]. Laser beam is a highly intensive and monochromatic beam. Laser beam is used as a machine tool for creating hole during laser drilling. During the process, laser beam is focused on surface of material, kinetic energy of laser beam converts in heat energy, and melting process takes place. Now, the molten material is removed by process of evaporation. The 
remaining unwanted material is removed by blown of highly assist gas pressure. Finally, precise drilled hole takes place on work piece [I. Choudahry et al., 2012 \& A. Dubey et al., 2008].

Laser beam machining process is generally used for machine advanced material like titanium, Ni based alloy, AISI316L, etc. Laser cutting has been used to machining of high-speed steel and AISI316L. The authors have seen kerf width formation with effect of cutting speed and power input on steel materials. Various researchers have studied the effect of parameters as pulse frequency (PF), power, gas pressure (GP), and cutting speed (CS) in formation of kerf width and heat affected zone on general metals [G. Gautam et al., 2018, K. Ghany et al., 2005, R. Goyal et al., 2016 \& A. Hascalik et al., 2013].

Few researchers found kerf width increase with improved laser power but decreasing it while increasing cutting speed. To cut 4130 steel through laser, PF plays a major role to reduce heat affected zone (HAZ) and kerf width (KW) [S. Kumar et al., 2006]. HAZ decreases while increasing the laser power to machining of SS304. KW reduces if CS increased [A. Lamikiz et al., 2005].

Researchers have seen the effect of GP and PF on recast layer formation. Also, they examined circularity of hole geometrical features during laser trepan drilling in IN718, Ti alloy, stainless steel, etc. Researchers have used CO2 and Nd: YAG laser to perform drilling operations and saw the effect of PF, GP, Current (C), pulse width, pulse mode, etc. on hole geometrical features like circularity and hole taper (HT) [D. Montgomery et al., 2015]. Researchers prepared scientifically designed experimental run using orthogonal array or CCD (central composite design) based on considering number of independent variables. Researchers also used hybrid approach to optimize their responses like HAZ and KW for laser cutting and HT for laser drilling. Artificial intelligence tools like fuzzy logic and genetic algorithm (GA) are used successfully to accomplish work for modelling and optimization of responses. Based on literature review, the present work is a study of geometric features of drilled hole of diameters $1 \mathrm{~mm}$ on AISI316L sheet. All experiments have been performed on pulsed Nd:YAG laser beam system. Four input parameters (GP, C, CS, and PF) and their effect on three responses have been decided. These responses are hole taper (HT), hole circularity at entrance (Cent), and exit sides (Cexit) of hole. There are hundreds of experimental combinations possible with four input parameters. To minimize the number of experiments with maximum information, CCD approach has been chosen. Minitab software has been used to prepare the design of experiment. Experimental data has been used to develop the empirical model.

\section{EXPERIMENTAL DESIGN AND SETUP LAYOUT}

Response surface methodology (RSM) is a statistical method of design of experiment. This method has been used for modeling and optimization purpose. Generally, this method is used to optimize engineering problems. There are many experimental methods in RSM, and central composite design (CCD) is one of them. This design is most effective design over other experimental designs. In CCD, a second-order regression model is prepared [A. Pandey et al., 2013]. For CCD, numbers of experiments are finalized with the below mentioned formula in equation 1.

$$
\mathrm{N}=\mathrm{K}^{2}+2 \mathrm{~K}+\mathrm{C}
$$

where $\mathrm{N}=$ number of experiments, $\mathrm{K}=$ number of input parameters (4), and $\mathrm{C}=$ number of central run (7). The total number of experiments (N) is 31 [M Radovanovic et al., 2011]. 
Table 1. Chemical Composition of AISI316L Sheet.

\begin{tabular}{|c|c|c|c|}
\hline Material & $\mathrm{Cr}$ & $\mathrm{Ni}$ & Mo \\
\hline$\%$ Composition & $17.06 \%$ & $10.17 \%$ & $2.1 \%$ \\
\hline
\end{tabular}

A $500 \mathrm{~W}$ Nd:YAG laser has been used. Its peak power is $5 \mathrm{~kW}$, and wavelength, $1064 \mathrm{~nm}$. AISI316L sheet of $1.8 \mathrm{~mm}$ thickness has been used for drilling operation. AISI316L plate of dimension is $150 \mathrm{~mm} * 100 \mathrm{~mm} * 1.8 \mathrm{~mm}$. Density $\left(\mathrm{g} / \mathrm{cm}^{3}\right)$, specific heat $\left(\mathrm{J} / \mathrm{kg}^{0} \mathrm{~K}\right)$, melting point temperature $\left({ }^{\circ} \mathrm{C}\right)$, thermal conductivity $\left(\mathrm{W} / \mathrm{m}^{0} \mathrm{~K}\right)$, and coefficient of thermal expansion $\left(1 /{ }^{\circ} \mathrm{C}\right)$ of AISI316L plate are 8, 500,1440,16.3, and 15.9, respectively. Chemical composition of work material is shown in Table 1. Input parameters' range has been decided on the basis of trialbased experiments through hole of $1 \mathrm{~mm}$ diameter. Range of input parameters with levels is given in Table 2. Due to some experimental limitations, it is not possible to consider all values of input parameters. In this situation, nearest values have been preferred for input parameters [N. Rajaram et al., 2003]. In the present work, all input parameter values for their level are very near to theoretical values.

Table 2. Input parameters and their levels.

\begin{tabular}{|c|c|c|c|c|c|c|c|}
\hline \multirow{2}{*}{ Symbol } & \multirow{2}{*}{$\begin{array}{c}\text { Input Parameters } \\
\text { (Abbreviations) }\end{array}$} & \multirow{5}{*}{ Unit } & \multicolumn{5}{|c|}{ Level } \\
\cline { 4 - 8 } & $\mathrm{GP}$ & $\left\{\mathrm{kg} / \mathrm{cm}^{2}\right\}$ & 6 & 7 & 8 & 9 & 10 \\
\hline $\mathrm{p}_{1}$ & $\mathrm{C}$ & $\{\mathrm{Amp}\}$ & 150 & 175 & 200 & 225 & 250 \\
\hline $\mathrm{p}_{2}$ & $\mathrm{CS}$ & $\{\mathrm{mm} / \mathrm{min}\}$ & 10 & 20 & 40 & 60 & 80 \\
\hline $\mathrm{p}_{3}$ & $\mathrm{PF}$ & $\{\mathrm{Hz}\}$ & 8 & 9 & 10 & 11 & 12 \\
\hline $\mathrm{p}_{4}$ & & &
\end{tabular}

\section{EVALUATION OF DRILLED HOLE QUALITY CHARACTERISTICS}

\section{Hole Diameter}

Hole dimeter has been measured from four different sides. It has been measured circumferentially at interval of $45^{\circ}$. Hole dimeter has been measured by Moticam series stereo microscope. After that, the average has been taken of four diameters $\mathrm{d}_{1}, \mathrm{~d}_{2}, \mathrm{~d}_{3}$, and $\mathrm{d}_{4}$ as shown in Figure 1 [Saini et al., 2018]. The same measurement process has been followed for all experiments. Hole diameter has been measured for top side and bottom side also. Microscopic image of drilled hole has been shown in Figure 1 and Figure 2.

\section{Hole Circularity (Cent, Cexit) and Hole Taper (HT)}

Laser drilled hole is created by using thermal energy of laser beam. Laser drilled hole boundary is not perfectly circular. Hole circularity at bottom and top side is measured by the given formulas in equation 2 and equation 3 . Drilled holes are not perfectly circular. Because of this reason, in the case of through hole, there will be some difference between top and bottom side diameter. It is measured by formula given in equation 4 . Hole taper depends upon sheet thickness [Saini et al., 2018]. 
Cent $=\left(D_{t}\right) \min /\left(D_{t}\right) \max$

Cent $=\left(\mathrm{D}_{\mathrm{b}}\right) \min /\left(\mathrm{D}_{\mathrm{b}}\right) \max$

$H_{T}=\frac{180}{\pi}\left\{\operatorname{Tan}^{-1}\left(\frac{D_{\text {ent }}-D_{\text {exit }}}{2 \mathrm{t}}\right)\right\}$

where $\mathrm{D}_{\mathrm{t}}=$ top side diameter, $\mathrm{D}_{\mathrm{b}}=$ bottom side diameter, $\mathrm{D}_{\text {ent }}=$ Top side diameter, $\mathrm{D}_{\text {exit }}=$ bottom side diameter, and $\mathrm{t}=$ sheet thickness.

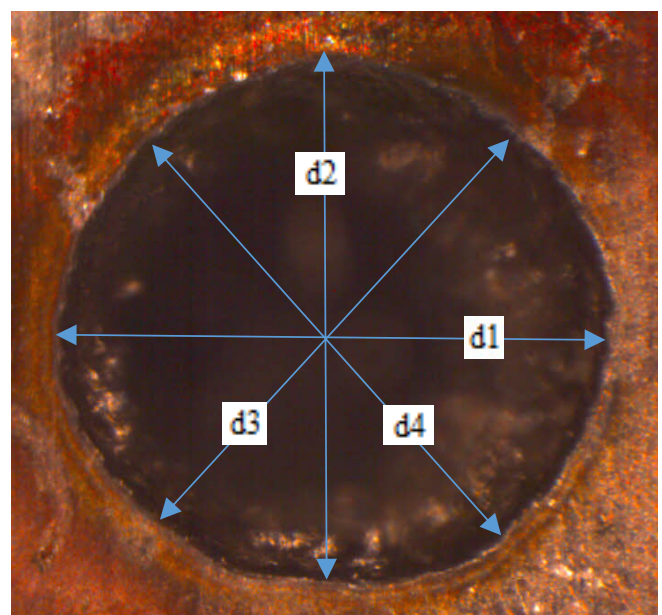

Figure 1. Microscopic image of top diameter.

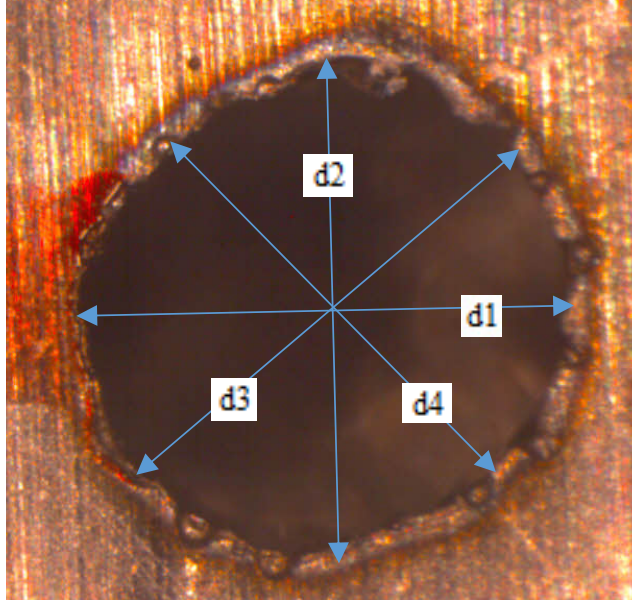

Figure 2. Microscopic image of bottom diameter.

\section{REGRESSION MODEL}

RSM is a mathematical tool that can be used to make a best model for multiparameters in experimental data and prepare an optimum experiment design. RSM is a trustful arithmetic technique for many applications. A mathematical relation has been prepared between input parameters and responses. This will help know the behavior of process parameters on response. The general second-order regression equation is given in equation 5 [R. Goyal et al., 2016].

$$
y_{k}=\alpha_{0}+\sum_{i=1}^{n} \alpha_{i} p_{i}+\sum_{i=1}^{n} \alpha_{i} p_{i i}^{2}+\sum_{i=1}^{n} \sum_{j=n+1}^{n} \alpha_{i j} p_{i} p_{j}
$$

where ' $\alpha$ ' are regression coefficients. ' $n$ ' is the number of input parameters. $y_{k}$ is response [S. Saini et al., 2018]. After checking acceptability of parameters, the values are given in Table 2. Second-order regression equations are developed for responses Cent, Cexit, and HT accordingly. General second-order regression equations are given in equations 6, 7, and 8 for responses Cent, Cexit, and HT, respectively, in uncoded units for AISI316L as follows:

$$
\begin{aligned}
& \text { Cent }=-1.672+0.2896 \mathrm{p}_{1}+0.00989 \mathrm{p}_{2}+0.00384 \mathrm{p}_{3}+0.0632 \mathrm{p}_{4}-0.01210 \mathrm{p}_{1}^{2}-0.000015 \mathrm{p}_{2}^{2}-0.000030 \mathrm{p}_{3}{ }^{2} \\
& -0.00053 \mathrm{p}_{4}^{2}-0.000332 \mathrm{p}_{1} * \mathrm{p}_{2}+0.000131 \mathrm{p}_{1}{ }^{*} \mathrm{p}_{3}-0.00302 \mathrm{p}_{1} * \mathrm{p}_{4}-0.000007 \mathrm{p}_{2} \mathrm{p}_{3}-0.000071 \mathrm{p}_{2} \mathrm{p}_{4} \\
& -0.000071 \mathrm{p}_{3} \mathrm{p}_{4}
\end{aligned}
$$


Cexit $=1.10-0.071 \mathrm{p}_{1}+0.01075 \mathrm{p}_{2}-0.00797 \mathrm{p}_{3}-0.190 \mathrm{p}_{4}+0.00093 \mathrm{p}_{1}{ }^{2}-0.000025 \mathrm{p}_{2}^{2}-0.000002 \mathrm{p}_{3}^{2}$ $+0.00343 \mathrm{p}_{4}^{2}-0.000579 \mathrm{p}_{1}^{*} \mathrm{p}_{2}+0.001247 \mathrm{p}_{1} * \mathrm{p}_{3}+0.01369 \mathrm{p}_{1} * \mathrm{p}_{4}+0.000057 \mathrm{p}_{2} * \mathrm{p}_{3}+0.000298 \mathrm{p}_{2} * \mathrm{p}_{4}$

$-0.001473 \mathrm{p}_{3} * \mathrm{p}_{4}$

$\mathrm{HT}=36.7-2.26 \mathrm{p}_{1}-0.2862 \mathrm{p}_{2}+0.1275 \mathrm{p}_{3}+1.95 \mathrm{p}_{4}-0.0360 \mathrm{p}_{1}{ }^{2}+0.000458 \mathrm{p}_{2}{ }^{2}-0.000411 \mathrm{p}_{3}{ }^{2}-0.0330 \mathrm{p}_{4}^{2}$ $+0.01644 \mathrm{p}_{1} * \mathrm{p}_{2}-0.01654 \mathrm{p}_{1} * \mathrm{p}_{3}-0.00067 \mathrm{p}_{3} * \mathrm{p}_{4}$

\section{MODEL VALIDATION}

\section{Theoretical Validation}

S-value and R-value are calculated for theoretical validation of any model. These values are given in Table 3 for individual model. If correlation coefficient's value (R-value) is more than 0.9 , then the predicted data will be acceptable. In the present case, $\mathrm{R}$-value is more than 0.9 for each model. Now, the data given in Table 2 is well fitted for all responses [R. Goyal et al., 2016 \& A. Hascalik et al., 2013].

Table 3. Regression analysis of developed model.

\begin{tabular}{|c|c|c|c|}
\hline Model Summary & S & R-sq & R-sq (adj) \\
\hline Cent & 0.0088 & $90.70 \%$ & $82.57 \%$ \\
\hline Cexit & 0.0269 & $93.22 \%$ & $87.29 \%$ \\
\hline HT & 0.2817 & $94.93 \%$ & $90.50 \%$ \\
\hline
\end{tabular}

Analysis of variance (ANOVA) has been used to test the capability of models. Its results have been shown for all models in Table 4. P-values are less than 0.5 for all three models. F-ratios are also calculated for source of regressions. F-ratios are 11.21, 15.72, and 21.41 for Cent, Cexit, and HT models, respectively. F-ratios for responses are more than critical F-ratio. Confidence level is $95 \%$ [W. Tiffany et al., 1985]. So, the developed experimental relations for all parameters are significant. It also acceptable for prediction of responses value.

Table 4. ANOVA result for Responses.

\begin{tabular}{|l|c|c|c|c|c|c|c|}
\hline \multirow{2}{*}{ Source } & \multirow{2}{*}{ DF } & \multicolumn{3}{|c|}{ F-Value } & \multicolumn{3}{c|}{ P-Value } \\
\cline { 3 - 8 } & & Cent & Cexit & Cent & Cexit & Cent & Cexit \\
\hline Regression & 14 & 11.15 & 15.72 & 11.15 & 15.72 & 11.15 & 15.72 \\
\hline Linear & 4 & 15.56 & 3.22 & 15.56 & 3.22 & 15.56 & 3.22 \\
\hline Square & 4 & 27.13 & 2.62 & 27.13 & 2.62 & 27.13 & 2.62 \\
\hline 2-Way Interaction & 6 & 2.92 & 12.51 & 2.92 & 12.51 & 2.92 & 12.51 \\
\hline Error & 16 & & & & & & \\
\hline Lack-of-Fit & 9 & 1.63 & 2.98 & 1.63 & 2.98 & 1.63 & 2.98 \\
\hline Pure Error & 7 & & & & & & \\
\hline Total & 30 & & & & & & \\
\hline
\end{tabular}




\section{Significant Factor Analysis}

ANOVA technique has been used to find out significant input parameters for the responses. Results have been shown in Table 5. Gas pressure and current are significant for Cent. Current and pulse frequency are significant for Cexit. Current and cutting speed are significant for HT.

Table 5. P-values of input parameters for responses.

\begin{tabular}{|l|c|c|c|}
\hline Process Parameters & Cent & Cexit & HT \\
\hline Gas Pressure & $\mathbf{0}$ & 0.601 & 0.125 \\
\hline Current & $\mathbf{0}$ & $\mathbf{0 . 0 4 1}$ & $\mathbf{0}$ \\
\hline Cutting Speed & 0.085 & 0.231 & $\mathbf{0 . 0 3 5}$ \\
\hline Pulse Frequency & 0.18 & $\mathbf{0 . 0 3 2}$ & 0.195 \\
\hline
\end{tabular}

\section{Experimental Validation}

Table 6. Mean prediction error for different responses.

\begin{tabular}{|c|c|c|c|c|c|c|c|c|c|c|c|c|c|}
\hline \multirow{2}{*}{$\begin{array}{l}\text { Exp. } \\
\text { No. }\end{array}$} & \multicolumn{4}{|c|}{ Input parameters } & \multicolumn{3}{|c|}{ Cent } & \multicolumn{3}{|c|}{ Cexit } & \multicolumn{3}{|c|}{$\mathrm{HT}$} \\
\hline & $\mathrm{p}_{1}$ & $\mathrm{p}_{2}$ & $\mathrm{p}_{3}$ & $\mathrm{p}_{4}$ & Pred. & Expe. & $\begin{array}{c}\% \\
\text { error }\end{array}$ & Pred. & Expe. & $\begin{array}{c}0 \\
\text { error }\end{array}$ & pred. & Exp. & $\begin{array}{c}\% \\
\text { error }\end{array}$ \\
\hline 1 & 7 & 175 & 20 & 11 & 0.93 & 0.92 & 1.29 & 0.90 & 0.93 & 3.49 & 7.95 & 7.57 & 5.01 \\
\hline 2 & 9 & 175 & 20 & 11 & 0.95 & 0.94 & 0.69 & 0.93 & 0.91 & 2.61 & 7.05 & 6.81 & 3.54 \\
\hline 3 & 7 & 225 & 20 & 11 & 0.96 & 0.95 & 1.48 & 0.95 & 0.95 & 0.35 & 5.27 & 5.32 & 1.03 \\
\hline 4 & 9 & 225 & 20 & 11 & 0.95 & 0.93 & 1.67 & 0.93 & 0.96 & 2.96 & 6.01 & 5.84 & 2.92 \\
\hline 5 & 7 & 175 & 60 & 11 & 0.95 & 0.93 & 1.71 & 0.67 & 0.65 & 3.44 & 8.47 & 8.53 & 0.73 \\
\hline 6 & 9 & 175 & 60 & 11 & 0.97 & 0.96 & 1.14 & 0.81 & 0.84 & 3.77 & 6.25 & 5.85 & 6.76 \\
\hline 7 & 7 & 225 & 60 & 11 & 0.96 & 0.94 & 2.57 & 0.84 & 0.86 & 2.08 & 6.26 & 5.92 & 5.78 \\
\hline 8 & 9 & 225 & 60 & 11 & 0.96 & 0.94 & 1.70 & 0.92 & 0.92 & 0.02 & 5.68 & 5.73 & 0.89 \\
\hline 9 & 7 & 175 & 60 & 11 & 0.95 & 0.93 & 1.71 & 0.67 & 0.67 & 0.36 & 8.47 & 8.61 & 1.70 \\
\hline 10 & 9 & 175 & 20 & 9 & 0.92 & 0.91 & 1.46 & 0.88 & 0.90 & 1.70 & 7.00 & 6.90 & 1.48 \\
\hline 11 & 7 & 225 & 20 & 9 & 0.94 & 0.91 & 2.85 & 0.93 & 0.93 & 0.08 & 5.80 & 5.75 & 0.86 \\
\hline 12 & 9 & 225 & 20 & 9 & 0.93 & 0.92 & 1.03 & 0.85 & 0.90 & 5.25 & 6.60 & 6.35 & 3.98 \\
\hline
\end{tabular}




\begin{tabular}{|c|c|c|c|c|c|c|c|c|c|c|c|c|c|}
\hline 13 & 7 & 175 & 60 & 9 & 0.92 & 0.89 & 2.39 & 0.80 & 0.80 & 0.50 & 8.41 & 8.14 & 3.37 \\
\hline 14 & 9 & 175 & 60 & 9 & 0.95 & 0.94 & 1.44 & 0.88 & 0.89 & 1.44 & 6.25 & 6.20 & 0.81 \\
\hline 15 & 7 & 225 & 60 & 9 & 0.94 & 0.92 & 2.36 & 0.94 & 0.97 & 3.51 & 6.84 & 7.09 & 3.47 \\
\hline 16 & 9 & 225 & 60 & 9 & 0.95 & 0.92 & 2.79 & 0.96 & 0.96 & 0.08 & 6.33 & 6.26 & 1.04 \\
\hline 17 & 6 & 200 & 40 & 10 & 0.92 & 0.91 & 0.88 & 0.87 & 0.91 & 4.71 & 7.26 & 7.16 & 1.44 \\
\hline 18 & 10 & 200 & 40 & 10 & 0.94 & 0.91 & 2.92 & 0.93 & 0.94 & 1.43 & 5.84 & 6.10 & 4.13 \\
\hline 19 & 8 & 150 & 40 & 10 & 0.93 & 0.92 & 0.65 & 0.76 & 0.78 & 2.34 & 9.15 & 9.41 & 2.81 \\
\hline 20 & 8 & 250 & 40 & 10 & 0.95 & 0.92 & 3.31 & 0.90 & 0.94 & 4.30 & 6.54 & 6.42 & 1.83 \\
\hline 21 & 8 & 200 & 10 & 10 & 0.94 & 0.91 & 3.01 & 0.94 & 0.94 & 0.44 & 6.24 & 6.61 & 5.63 \\
\hline 22 & 8 & 200 & 80 & 10 & 0.94 & 0.93 & 1.38 & 0.83 & 0.88 & 5.61 & 6.16 & 6.12 & 0.65 \\
\hline 23 & 8 & 200 & 40 & 12 & 0.99 & 0.97 & 2.45 & 0.88 & 0.93 & 4.89 & 6.30 & 6.51 & 3.29 \\
\hline 24 & 8 & 200 & 40 & 8 & 0.95 & 0.94 & 1.15 & 0.93 & 0.94 & 1.14 & 6.84 & 6.77 & 0.96 \\
\hline 25 & 8 & 200 & 40 & 10 & 0.98 & 0.95 & 2.71 & 0.89 & 0.90 & 0.76 & 6.70 & 6.62 & 1.17 \\
\hline 26 & 8 & 200 & 40 & 10 & 0.98 & 0.96 & 1.64 & 0.89 & 0.93 & 3.96 & 6.70 & 6.41 & 4.49 \\
\hline 27 & 8 & 200 & 40 & 10 & 0.98 & 0.96 & 1.64 & 0.89 & 0.89 & 0.36 & 6.70 & 6.80 & 1.51 \\
\hline 28 & 8 & 200 & 40 & 10 & 0.98 & 0.95 & 2.71 & 0.89 & 0.93 & 3.96 & 6.70 & 6.66 & 0.56 \\
\hline 29 & 8 & 200 & 40 & 10 & 0.98 & 0.97 & 0.59 & 0.89 & 0.90 & 0.76 & 6.70 & 6.91 & 3.07 \\
\hline 30 & 8 & 200 & 40 & 10 & 0.98 & 0.97 & 0.59 & 0.89 & 0.89 & 0.36 & 6.70 & 6.49 & 3.20 \\
\hline 31 & 8 & 200 & 40 & 10 & 0.98 & 0.96 & 1.64 & 0.89 & 0.93 & 3.96 & 6.70 & 6.47 & 3.52 \\
\hline
\end{tabular}

Experimental validation: experimental data will be compared with the predicted regression model. Mean prediction percentage error (MPPE) will be found out for all the responses.

MPPE value is calculated by the formula given in equation 9:

$\mathrm{MPPE}=($ Experimental value-Predicted value $) * 100$

(Experimental value)

The comparison result has been shown in Table 6 with prediction error for different responses. In Table 6, 'Pred,' 'Expe,' and '\%' error are indicating predicted, experimental, and percentage error value for each response, respectively. MPPE found for responses Cent, Cexit, and HT is $1.8 \%, 2.2 \%$, and $2.8 \%$, respectively. All these values 
are in the range of acceptable limit. It is clear that all developed models are reliable and acceptable. Now, these models may be used as predicted models [B. Yilbas 1996 \& B. Yilbas 2008].

\section{PARAMETRIC ANALYSIS}

\section{Improving Circularity at Top (Cent)}

Hole circularity was always an important response in hole features due to thermal energy of laser beam used in hole formation. Here, gas pressure and current are significant parameters for hole circularity at entrance (Cent) from Table 5. Response plot is shown in Figure 3.

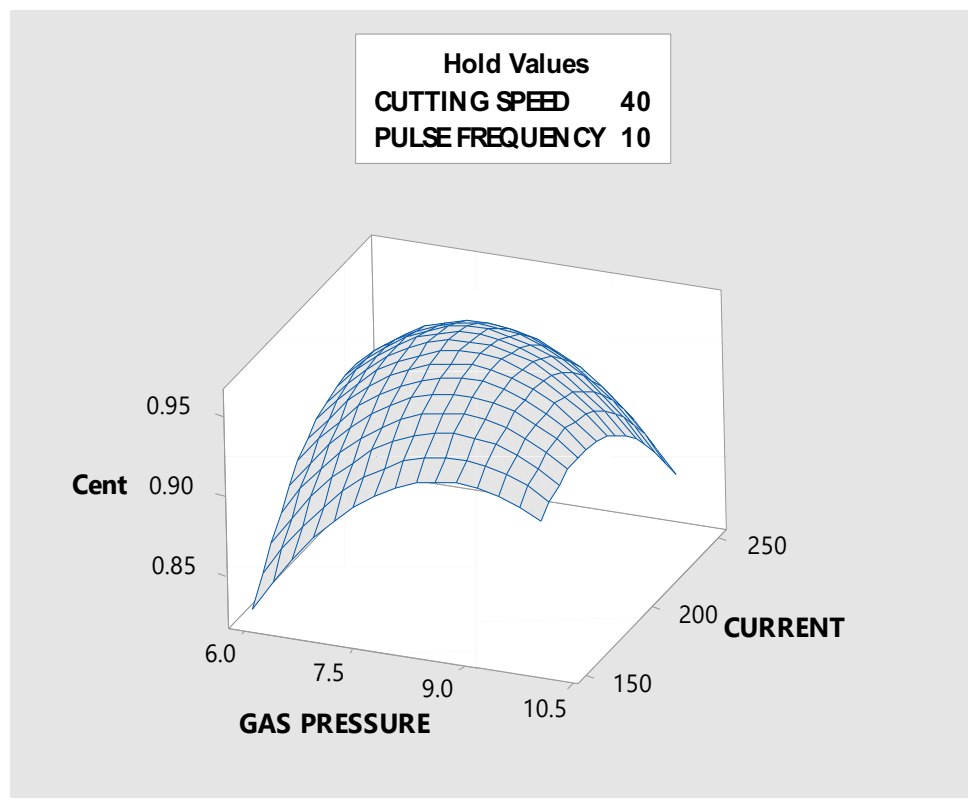

Figure 3. Surface Plot Cent vs Current vs Gas pressure.

From Figure 3, Cent first increases with increasing gas pressure and current till mid-range of these parameters. After that, Cent is decreasing with increasing gas pressure and current. Maximum Cent is 0.97 (experimental value) at $8 \mathrm{~kg} / \mathrm{cm} 2$ gas pressure and 200 A current.

While increasing current will increase laser power that will help to melt the metal at top surface of work piece, simultaneously, increased gas pressure will remove molten metal from the surface as earliest possible, but while increasing current above 200A and gas pressure above $8 \mathrm{~kg} / \mathrm{cm} 2$. In this condition, the material will melt or burn rapidly, and the melting temperature of around circumference of hole will increase. High gas pressure will remove unwanted material very quickly. So, the molten material will remove more quantity that will reduce circularity at top.

\section{Improving Circularity at Bottom (Cexit)}

Pulse frequency and current are significant parameters for improving hole circularity at bottom side. Response surface plot has been shown in Figure 4 for the same. In this response surface plot, it can be observed that the behavior 
of current for Cexit is the same as that for Cent. In this case, as the increase in current increases circularity till midrange, circularity is decreasing with increasing current.

Simultaneously, the increase in pulse frequency also increases exit circularity till maximum value of pulse frequency. Maximum value of Cexit is 0.96 (experimental value) at current $200 \mathrm{~A}$ and pulse frequency $9 \mathrm{~Hz}$. Increase in pulse frequency increases repetition rate of laser beam. So, penetration rate of laser beam will increase. Simultaneously, current is increased, and then unwanted material will melt in less time and be removed quickly from material surface. That will improve hole circularity.

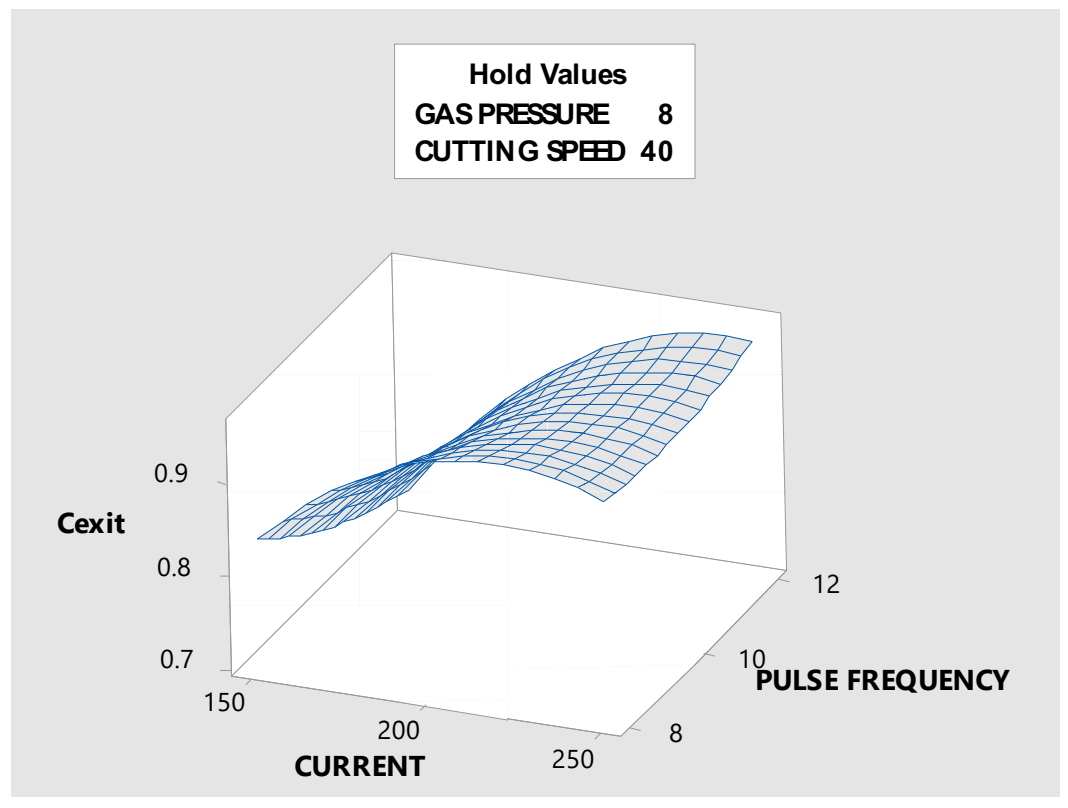

Figure 4. Surface plot Cexit vs Pulse frequency vs Current.

\section{Improving Hole Taper (HT)}

Current and CS are significant parameters for hole taper. Converging and diverging properties of laser beam give taperness during hole making operation. The minimum value of HT will help give uniform hole diameter (top to bottom); it improves hole feature. Its significant parameters have been discussed earlier. Response surface plot has been shown in Figure 5 for the same. From Figure 5, it can be seen clearly that the hole taper is decreasing with increasing current. Cutting speed is increased and will increase hole taper. The maximum value of current with low cutting speed decreases hole taper. Hole taper $5.32^{\circ}$ at current is $200 \mathrm{~A}$, and cutting speed is $20 \mathrm{~mm} / \mathrm{min}$. The high current value will increase heat energy, and AISI316L is highly thermal conductive material, and the molten material will be removed rapidly. Simultaneously, less cutting speed and low gas pressure (Table 6) can not remove melted material from surface and remaining material recast and adhere around the hole. So, hole diameter reduces and difference between hole diameter both sides will be decreased. 


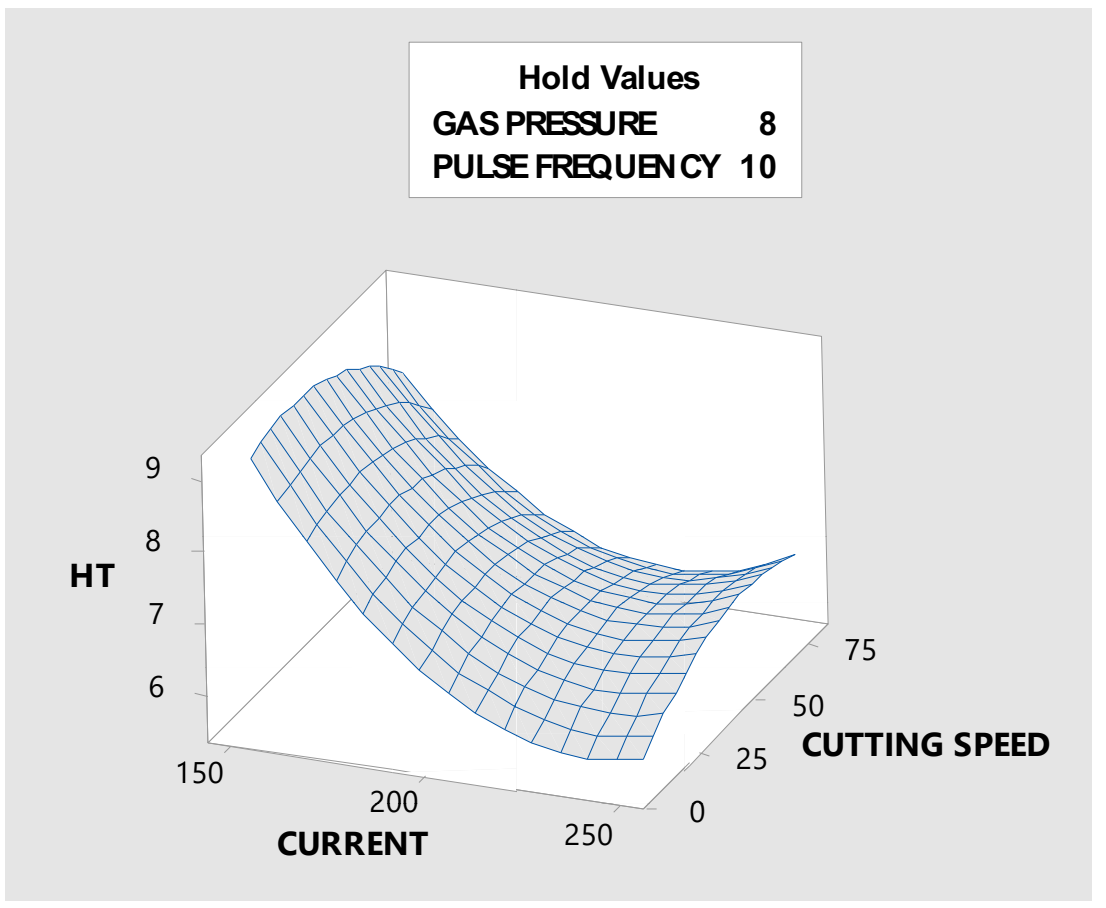

Figure 5. Surface Plot HT vs Cutting Speed vs Current.

\section{CONCLUSION}

THE Design of experiment has been used to prepare an experimental model for modelling of laser drilling of AISI316L sheet for $1 \mathrm{~mm}$ hole diameter. RSM and ANOVA techniques have been used to validate all responses and input parameters.

The following outcomes have been found in this research work.

a. Regression model for all responses Cent, Cexit, and HT is acceptable and trustworthy. P-values for all responses are below 0.05 .

b. Mean prediction percentage error for responses Cent, Cexit, and HT is $1.8 \%, 2.2 \%$, and 2.8\%, respectively.

c. Current and gas pressure are found to be significant process parameters for circularity at top side (Cent). Maximum Cent is 0.97 (experimental value) at $8 \mathrm{~kg} / \mathrm{cm}^{2}$ gas pressure and 200 A current. Current and pulse frequency are found significant process parameters for circularity at bottom side (Cexit). Maximum value of Cexit is 0.96 (experimental value) at current $200 \mathrm{~A}$ and pulse frequency $9 \mathrm{~Hz}$.

d. Current and cutting speed are significant parameters for hole taper. Minimum value of hole taper $5.32^{0}$ at current is $200 \mathrm{~A}$, and the cutting speed is $20 \mathrm{~mm} / \mathrm{min}$.

\section{ACKNOWLEDGMENTS}

The authors would like to thank Dr. B.N. Upadhyay, Mr. A. Choubey and their team to support and provided facilities to perform experiments at Solid State Laser Division, Raja Ramanna Centre for Advanced Technology (RRCAT), Indore, Madhya Pradesh, India. Furthermore, sincere gratitude towards Rajasthan University Jaipur, India for support given in Material testing. 


\section{REFERENCES}

Audouard E, Lopez J, Ancelot B, Gaudfrin K, Kling R, Mottay E 2017. Optimization of surface engraving quality with ultrafast laser. Journal of Laser Applications. 29 (2).

Bharatish A, Murthy HN, Anand B, Madhusoodana CD, Praveena GS, Krishna M. 2013. Characterization of hole circularity and heat affected zone in pulsed $\mathrm{CO}_{2}$ laser drilling of alumina ceramics. Optics and Laser Technology. 53: 22-32.

Cekic A, Begic-Hajdarevic D, Kulenovic M, Omerspahic A. 2014. $\mathrm{CO}_{2}$ laser cutting of alloy steels using N2 assist gas, Procedia Engineering. 69: 310-315.

Choudhury IA, Chong WC, Vahid G. 2012. Hole qualities in laser trepanning of polymeric materials. Optics and Lasers Engineering. 50 (9): 1297-1305.

Dubey AK, Yadava V. 2008. Laser beam machining - a review. International Journal of Machine Tools and Manufacture. 48 (6). 609-628.

Gautam GD, Pandey AK. 2018. Pulsed Nd:YAG laser beam drilling: A review. Optics and Laser Technology. 100: 183-215.

Ghany KA, Newishy M. 2005. Cutting of $1.2 \mathrm{~mm}$ thick austenitic stainless steel sheet using pulsed and CW Nd:YAG laser. Journal of Mtls Processing Technology. 168 (3): 438-447.

Goyal R, Dubey AK. 2016. Modelling and optimization of geometrical characteristics in laser trepan drilling of titanium alloy. Journal of Mechanical Science and Technology. 30: 1281-1293.

Hascalik A, Ay M. 2013. $\mathrm{CO}_{2}$ laser cut quality of Inconel 718 nickel - based superalloy. Optics and Laser Technology. 48: 554-564.

Lamikiz A, Lacalle D, Sa JA, Lo LN. 2005. $\mathrm{CO}_{2}$ laser cutting of advanced high strength steels (AHSS). Applied Surface Science. 242: 362-368.

Montgomery DC. 2015. Design and analysis of experiments. Wiley.

Pandey AK, Dubey AK. 2013. Fuzzy expert system for prediction of kerf qualities in pulsed laser cutting of titanium alloy sheet, Machining Science and Technology. 17 (4): 545-574.

Radovanovic MMM. 2011. Experimental investigations of $\mathrm{CO}_{2}$ laser cut quality: A review. Nonconventional Technologies.4.

Rajaram N, Sheikh-Ahmad J, Cheraghi S. 2003. $\mathrm{CO}_{2}$ laser cut quality of 4130 steel. International Journal of Machine Tools and Manufacture. 43 (4): 351-358.

Saini SK, Dubey AK, Upadhyay BN, Choubey A. 2018. Study of hole characteristics in Laser Trepan Drilling of ZTA. Optics and Laser Technology. 103: 330 -339.

Tiffany WB. 1985. Drilling, Marking and Other Applications for Industrial Nd:YAG Lasers. SPIE, Application of High-powered Laser. 527: 28-36.

Yilbas BS. 1996. Experimental investigation into laser cutting parameters. Journal of materials processing technology. 58: 323-330.

Yilbas BS. 2008. Laser cutting of thick sheet metals: effects of cutting parameters on kerf size variations. Journal of materials processing technology. 201: 285-290. 